\title{
Hoje a aula é na rua: as ressignificações do espaço de ensino
}

\author{
Luiza Bedê Barbosa \\ Cinthia Yuri Galelli
}

Resumo: Neste artigo, analisaremos, a partir da Análise do Discurso francesa, especialmente do pensamento desenvolvido por Michel Foucault, o enunciado hoje a aula é na rua, que circulou durante as ocupações das escolas estaduais paulistas em 2015. A atividade analítica ressaltará a singularidade do enunciado nas mobilizações estudantis, discutindo as ressignificações dos termos aula e rua a partir do cotejo entre as formações discursivas do ensino tradicional e do movimento estudantil. Observaremos também as implicações que as formações discursivas em questão produzem nos sujeitos secundaristas.

Palavras-chave: Formação discursiva. Ensino tradicional. Movimento estudantil.

Abstract: Based on the theoretical support of the French discourse analysis, specially the thought developed by Michel Foucault, will be analysed the statement "hoje a aula é na rua" (the class is outside today), which was spread during the occupation of the São Paulo state schools in 2015. The analytical procedure will highlight the singularity of the enunciation present in the students' movement, discussing the re-significances of the terms "class" and "street" from the comparison between the discursive formations of traditional teaching and the one of students movement. We will also observe the implications that these discursive formations produce in secondary subjects.

Keywords: Discursive formation. Traditional teaching. Student movement.

Resumen: En este artículo analizaremos a partir del análisis francés del discurso, especialmente del pensamiento desarrollado por Michel Foucault, el enunciado "Hoy la clase es en la calle", que circuló durante las ocupaciones de las escuelas públicas del estado de São Paulo en 2015. La actividad analítica destacará la singularidad de ese enunciado en los movimientos estudiantiles y discutirá las resignificaciones de los términos "clase" y "calle" a partir del cotejo entre las formaciones discursivas de la enseñanza tradicional y del movimiento estudiantil. Observaremos también las implicaciones que dichas formaciones discursivas producen en los sujetos secundaristas.

\footnotetext{
1 Doutoranda no Programa de Pós-graduação em Linguística e Língua Portuguesa da Faculdade de Ciências e Letras da Universidade Estadual Paulista "Júlio de Mesquita Filho" (UNESP/Araraquara) com o apoio da Capes.

2 Doutoranda no Programa de Pós-graduação em Linguística e Língua Portuguesa da Faculdade de Ciências e Letras da Universidade Estadual Paulista "Júlio de Mesquita Filho" (UNESP/Araraquara) com o apoio da Capes.
} 
Palabras-clave: Formación Discursiva. Enseñanza tradicional. Movimiento estudiantil

\section{Considerações iniciais}

O segundo semestre de 2015 foi marcado pelas diversas manifestações de estudantes da rede pública de ensino do estado de São Paulo. As mobilizações foram iniciadas a partir da imposição da Secretaria de Educação do estado de uma "reorganização escolar", a qual afetaria diretamente a vida de milhares de crianças e jovens - e de suas famílias -, que seriam transferidos para outras unidades de ensino, muitas vezes distantes de seus domicílios. Os estudantes se mobilizaram contra essa imposição por meio de ocupações de escolas e de manifestações de rua, exigindo que suas reivindicações fossem ouvidas pelos órgãos competentes. A partir desse acontecimento, emergem discursos de resistência produzidos pelos estudantes, materializados em diversos enunciados, dos quais analisaremos um em específico: Hoje a aula é na rua (ver figuras 1 e 2).

Figura 1

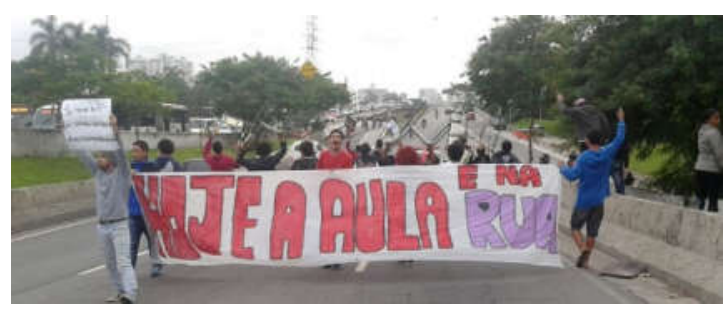

Fonte: O mal-educado (Facebook)
Figura 2

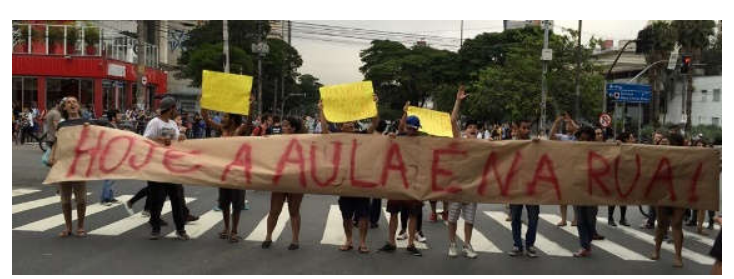

Fonte: O mal-educad (Facebook)

O objetivo deste artigo é analisar o enunciado em questão levando em consideração que essa atividade exige de nós uma leitura que perscrute os sentidos mobilizados tanto pelo termo aula quanto pelo termo rua que, colocados em relação coordenada no intradiscurso, nos permitirá ativar o interdiscurso que reemerge nas mobilizações estudantis em tempo e espaço 
distintos, já que o enunciado que estamos nos propondo analisar não é novo 3 . Nossa intenção não é apreender o texto fundador, a origem desse enunciado, tampouco investigar sobre a primeira vez que ele apareceu, mas sim acessar e analisar os sentidos que ele produz nesse acontecimento preciso - durante as ocupações das escolas paulistas - por meio das formações discursivas em que esse enunciado atua e na sua ressignificação na trama histórica.

Para lograr esse objetivo, traremos como subsídio teórico a visão da análise do discurso francesa, em torno do pensamento de Michel Foucault (2000; 1999), que trata das estratégias de normalização dos discursos e dos sujeitos construídas pelos dispositivos ${ }^{4}$, no caso, o escolar, produzindo uma forma de ser sujeito para os alunos e, ao mesmo tempo, criando para eles novas possibilidades de subjetivação. Outras bases teóricas serão oferecidas pelas (re)formulações de alguns conceitos já trabalhados no campo da AD de J. J. Courtine (2009), que confere atenção especial à noção de Formação Discursiva, doravante FD.

Para isso, traremos à tona discussões sobre o conceito de poder disciplinar (FOUCAULT, 1999), a fim de melhor compreender as práticas escolares que atuam sobre os sujeitos. Além desses elementos, traremos o conceito de praça pública elaborado por Mikhail Bakhtin (1997), pelo qual buscaremos compreender a dinâmica que o termo rua desempenha na formação discursiva dos movimentos sociais.

\section{Subsídios teóricos}

\footnotetext{
${ }^{3}$ Ressaltamos que a formulação Hoje a aula é na rua é recorrente nas mobilizações estudantis, não somente no Brasil, mas também em outros países da América Latina, como Venezuela (BELISARIO, 2014) e Chile (THE CLINIC, 2011).

Segundo Foucault, dispositivo é uma rede onde se articulam elementos como instituições, formas arquitetônicas, urbanísticas, decisões regulamentares políticas, as práticas jurídicas, as medidas administrativas, enunciados filosóficos, científicos etc. enfim, o dispositivo diz respeito "às práticas [discursivas e não discursivas] atuando como um aparelho, uma ferramenta, constituindo sujeitos e os organizando" (DREYFUS; RABINOW, 1995, p. 135).
} 
Segundo Foucault (2000), todo enunciado é histórico e, por isso, ele deve ser analisado a partir das regras de formação que possibilitam que ele seja, em um dado momento histórico, materializado. Justamente por ser histórico, o filósofo afirma que nenhum enunciado é novo, porque "o novo não está no que é dito, mas no acontecimento de sua volta" (FOUCAULT, 2000, p. 26). Isso porque os enunciados são marcados pela relação que eles estabelecem com outros enunciados, que vão participando da construção dos sentidos de uma textualidade. Desse modo, a atividade de análise trata de

[...] compreender o enunciado na estreiteza e singularidade de sua situação; de determinar as condições de sua existência, de fixar seus limites da forma mais justa, de estabelecer suas correlações com outros enunciados a que pode estar ligado. (FOUCAULT, 2000, p.31)

A partir do nosso marco teórico, julgamos que é tarefa da Análise do Discurso (AD) explicitar as formações e as transformações históricas dos discursos que vão implicar na produção de sujeitos que, para enunciar, se inscrevem em diferentes FDs, quer estejam elas sustentando o discurso da "normalidade" de instituições estabilizadas, quer estejam permitindo a existência de enunciados de resistência a tal "normalidade", que objetivam os sujeitos.

Assim, partiremos do pressuposto que analisar o discurso é observar como a história está materializada na linguagem, é entender que língua e história se articulam tecendo redes de significação e que, por isso, os sentidos não são livremente interpretados, mas regulados por condições específicas, que possuem determinações histórico-sociais. O discurso, dessa forma, não é o produto de uma individualidade, não existe interno ao sujeito, não o constitui por dentro, mas é uma construção social e histórica.

O conceito de formação discursiva foi formulado pela primeira vez em 1969 por Michel Foucault em sua obra A Arqueologia do saber, de onde destacamos a definição do próprio autor:

No caso em que se puder descrever [...] semelhante sistema de dispersão, no caso em que entre os objetos, os tipos de enunciação, os conceitos, as escolhas temáticas, se poderia definir uma regularidade (uma ordem, correlações, posições e funcionamentos, transformações), 
dir-se-á, por convenção, que se trata de uma formação discursiva. (FOUCAULT, 200o, p.43)

Dentro da $\mathrm{AD}$, no entanto, esse conceito sofreu transformações que tiveram como eixo central a articulação entre regularidade e dispersão (GREGOLIN, 2011). Essas transformações - conduzidas cada vez mais para a ideia de heterogeneidade - têm como o principal formulador J.J. Courtine (2009), que aproxima a proposta inicial de Foucault ao uso que lhe dá Pêcheux. Essa aproximação é importante porque consegue articular o funcionamento linguístico com posições históricas, já que os enunciados não podem ser interpretados de forma isolada de outros, proveniente de campos distintos do saber, caracterizando a dispersão de que fala Foucault (2000).

Dessa maneira, tomamos a FD como um conjunto de enunciados que se articulam, formando as condições de produção para certos discursos, e que são impulsionados pela memória. Para Foucault (2000), todo enunciado possui um domínio associado, ou seja, outros campos do saber que repetem, refutam, negam, transformam esses mesmos enunciados.

Não podemos separar o conceito de FD da noção de sujeito. Para Foucault, o sujeito sempre enuncia, de acordo com a sua posição, a partir de uma dada formação discursiva. Neste trabalho, como veremos adiante, o enunciado analisado mobiliza sentidos de termos que podem ser encontrados em dois domínios diferentes: os termos aula e rua podem assumir sentidos distintos ao serem enunciados a partir da FD do ensino tradicional ou a partir da FD do movimento estudantil. Ao enunciar Hoje a aula é na rua, portanto, o sujeito se desloca da FD do ensino tradicional para inscrever-se na FD do movimento estudantil.

Outra noção que utilizaremos neste trabalho e que está estreitamente ligada à de FD é a noção de memória, que abordaremos a partir do termo foucaultiano "domínio de memória" (FOUCAULT, 200o), que diz respeito não a uma memória individual, tratada pela neurociência ou pelas ciências cognitivas, mas uma memória social e coletiva, que entrelaça a linguagem com a história. Segundo Sá (2015, p. 51) 
De acordo com Foucault [200o], todo enunciado tem em si um campo de memória, ele apresenta uma série de formulações distintas e dispersas que forma no seu conjunto um domínio de memória. É essa rede de formulações que abarca um domínio de memória que dá lugar ao que Foucault chama de formação discursiva. É interessante, então, notar que, em Foucault, uma noção de memória (e uma reflexão sobre a memória) não está no cerne de suas discussões, não é central, mas ela está presente para pensar conceitos fundamentais como enunciado, discurso e formação discursiva.

É nesse sentido que usaremos o conceito de memória neste trabalho, com o intuito de mostrar que o discurso tece com a língua e a história redes de significação, permitindo a emergência e a repetição dos enunciados a partir de uma FD.

\section{A normalidade do ensino tradicional}

$\mathrm{O}$ que faz com que interpretemos o enunciado aula na rua como uma atualização dos termos aula e rua é o fato de esses dois termos terem os sentidos instaurados, no Brasil, a partir da FD do ensino tradicional. A concepção mais recorrente no país está relacionada a um ideal iluminista. Assim, o termo aula é concebido como um momento de transmissão de conhecimento daquele que porta um saber dirigido àquele que ainda não atingiu a ilustração, ou seja, o aluno. De acordo com o dicionário, o termo aula possui as seguintes definições:

(1) ant. palácio do soberano, a corte, o conjunto dos cortesãos. (2) exposição sobredeterminada área do conhecimento feita por professores e dirigida a um ou mais alunos, em geral em estabelecimento de ensino. (3) sala em que professor leciona; sala de aula, classe. (4) p.met. classe, turma. (5) parte de um programa de ensino, no conjunto de um curso, transmitida aos alunos por professor ou por texto. (6) ação, gesto, palavra ou obra que constitui um ensinamento, uma lição. (HOUAISS, 2009, p. 221)

Como podemos observar, nem todas as definições fazem referência à aula como sendo dada especificamente em um espaço fechado, dentro de uma escola ou centro de ensino. No entanto, em se tratando da escola pública brasileira, a concepção naturalizada de aula está diretamente relacionada ao espaço escolar, 
geralmente em uma sala específica, com lousa, giz, carteiras, onde os alunos que dela participam estão classificados por turmas de acordo com as séries determinadas pelo Ministério da Educação e pelas Secretarias dos estados. Tanto é assim que quando a aula não acontece nesses espaços pré-determinados, ela precisa estar acompanhada de outros termos explicativos: aula ao ar livre (fora do espaço "normal" que é sala), aula aberta (que pode significar tanto fora do espaço da sala de aula ou acessível a outros públicos que não aquele previamente selecionado) ou aula prática (geralmente ministrada fora da sala, dependendo do conteúdo a ser desenvolvido).

Portanto, o termo aula, quando enunciado a partir da FD do ensino tradicional, traz à tona a ideia de espaço (sala de aula, escola) mais do que a função que ela possui, como as trocas de aprendizagem sobre algum conteúdo, esses geralmente divididos em matérias. Em outras línguas latinas como o italiano e o espanhol, por exemplo, a palavra aula é usada justamente e exclusivamente para identificar a sala de aula, enquanto o momento de lecionar e aprender fica a cargo dos termos classe e clase, respectivamente. Em português, na maioria das definições encontradas no Houaiss (2009), o termo aula está relacionado a um espaço determinado, como uma sala ou um estabelecimento de ensino e ministrada por um professor.

Nesse sentido, não podemos desvincular o espaço em que acontece a aula, a sala de aula, de todo o espaço físico escolar (e dos objetos ali presentes), sejam em escolas, colégios, institutos e universidades, como os corredores, carteiras, lousas, filas etc. Quanto ao aspecto hierárquico, aula também nos remete às figuras do diretor, do coordenador, do inspetor (encarregado de cuidar da ordem) e do professor, que cuida tanto da ordem em sala de aula, quanto dos conteúdos que serão ali trabalhados. Na maneira como a aula tradicional se organiza, ela está totalmente centrada na figura do professor, o que é constatável simplesmente observando a disposição física dos componentes da sala de aula, em que ele, quando não está em um degrau acima dos alunos, tem a sua mesa e a lousa em posição contrária às carteiras, o que lhe permite ser visto, ao explicar uma matéria, e, ao mesmo tempo, vigiar. 
A hierarquia, portanto, serve à organização das tarefas escolares, funcionando como uma fonte de vigilância e de autoritarismo. Ou seja, o espaço escolar concentra um poderoso mecanismo de exercício de poder, que ordena e classifica os sujeitos e os objetiva por meio de saberes produzidos ao longo da história da educação e influencia a construção de suas subjetividades.

Para pensarmos a questão do espaço, remontaremos às primeiras instituições escolares instaladas no país, no final do século XIX, logo após a Proclamação da República, que conjuntamente com outros acontecimentos históricos e discursivos, alterou o cotidiano das pessoas, em suas práticas discursivas e não discursivas e também o aspecto físico das cidades, como assinala a Gregolin:

O cenário brasileiro no final do século XIX e meados do século XX estava convulsionado por grandes transformações que abrangiam um largo escopo: o campo da política (fim da monarquia e implantação da República); o da reorganização do trabalho (abolição dos escravos e chegada de trabalhadores europeus); o do reordenamento dos espaços urbano / rural e a remodelação das cidades; e o da economia (auge da cultura do café no sul e sudeste e o ciclo da borracha no norte). Era, portanto, um movimento amplo de transformações que atingiu profundamente as relações sociais e o cotidiano dos brasileiros, (GREGOLIN, 2015, p. 12)

Para os ideários republicanos, a instalação do prédio escolar foi um fator significativo na paisagem urbana em prol da construção de uma memória do Brasil de modernidade com ares europeus, a partir da regularidade das fachadas, da localização da escola na cidade, da sua amplitude, mas principalmente da sua funcionalidade (GREGOLIN, 2015). Esses ideais foram materializados na implantação do dispositivo escolar sob a forma de uma rede de prédios como objetos visíveis que abrigaram enunciados formuláveis, expressando forças em disputa para a produção de subjetividades: "visibilidade, enunciabilidade, linhas de força e processos de subjetivação: eis os vetores ou tensores desse dispositivo que expressava os valores do progresso e da modernidade de um "novo Brasil"' (GREGOLIN, 2015, p. 13).

Na obra Vigiar e Punir (1999), Foucault nos mostra, ao explicar o funcionamento da sociedade disciplinar - caracterizada pela estratégia da vigilância -, que é possível controlar os corpos por meio do controle dos espaços, 
da organização do tempo, da produção de saber e do seu registro, como as avaliações, as fichas de controle etc., denominadas por Gregolin (2015, p. 19) como "materialidades que mostram o acúmulo do saber produzindo poder".

O filósofo francês dedica grande parte da sua obra, sobretudo na já citada obra Vigiar e Punir (1999), às relações de poder estabelecidas no início do século XX nessas instituições, que tinham como um de seus objetivos a produção de corpos dóceis, úteis e submissos, ou segundo as palavras do próprio autor, a transformação do corpo social em "multidões confusas, inúteis ou perigosas em multiplicidades organizadas" (FOUCAULT, 1999, p. 135). A disciplina pode ser definida como uma anatomia política, em que o corpo é encarado como uma máquina, cujas aptidões serão ampliadas, suas forças serão extorquidas e cujos movimentos, gestos e comportamentos serão manipulados. Essa mecânica do poder disciplinar incide sobre os corpos sob o procedimento da vigilância, buscando a ordem, extraindo tempo de trabalho e alta produtividade (MENEGHETTI; SAMPAIO, 2016). Esse procedimento deve ser o mais econômico possível, por isso é estendido a outros aparelhos sociais, como citamos anteriormente, como o industrial, o pedagógico, o militar, o médico etc., buscando o máximo de rendimento e lucro.

Embora não tenha tido tempo de se ocupar sobre esse tema, o próprio Foucault reconheceu, em seus últimos escritos, que esse tipo de sociedade disciplinar, de confinamento, que acabamos de descrever, estava tomando outra configuração em razão dos meios tecnológicos e da pré-sociedade da informação.

Hoje, o controle é menos severo e mais refinado, sem ser, contudo,
menos aterrorizador. Durante todo o percurso de nossa vida, todos nós
somos capturados em diversos sistemas autoritários; logo no início na
escola, depois em nosso trabalho e até em nosso lazer. Cada indivíduo,
considerado separadamente, é normatizado e transformado em um
caso controlado por um IBM. Em nossa sociedade, estamos chegando a
refinamentos de poder os quais aqueles que manipulavam o teatro do
terror [nas execuções penais públicas] sequer haviam sonhado
(FOUCAULT, 2003, p. 307).

É o pensador Gilles Deleuze (DELEUZE, 1992) quem vai se debruçar sobre esse conceito de sociedade de controle mostrando que, pelos escritos de Foucault, a sociedade disciplinar funcionava nos espaços fechados, numa 
arquitetura de enclausuramento, como a escola, a prisão, os hospitais, as fábricas etc. e pela ordenação do tempo de trabalho em horas (COSTA, 2004). A sociedade de controle, por sua vez, pode ser caracterizada pela ausência de limites espaciais e, até mesmo, temporais, definidos. A partir da nova maneira como o capital se estrutura desde a década de 1970 - que poderíamos incluir aspectos como os avanços tecnológicos criando a chamada sociedade da informação ou do capitalismo do saber -, cada vez mais, o trabalhador mescla o tempo de trabalho com o tempo de lazer, assim como o aluno em relação aos seus estudos: "os indivíduos nunca conseguiriam terminar coisa nenhuma, pois estariam sempre enredados numa espécie de formação permanente, de dívida impagável, prisioneiros em campo aberto" (COSTA, 2004, p. 161).

Na sociedade disciplinar, uma das estratégias da disciplina é a vigilância que mantém o poder opaco e os indivíduos visíveis de forma hierarquizada, ou seja, o poder se manteria fora do alcance dos indivíduos, que são constantemente observados, ou seja, implica um observador. Nas sociedades de controle, há mecanismos menos explícitos que os praticados pela sociedade disciplinar, mas que possuem um grande alcance e eficiência, porque agora a potência de um corpo é controlada a partir de dentro, a vigilância é virtual. Isso quer dizer que a disciplina foi incorporada pelos indivíduos, sem a presença de uma autoridade investida de poderes para impor os comportamentos.

Apesar de estarmos cientes desse modo de controle atuando sobre as subjetividades dos sujeitos, não podemos deixar de levar em consideração o fato de que, enquanto espaço e organização física, a escola, na contemporaneidade, não se desvencilhou do modelo disciplinar que a caracterizou, ainda que tenha sofrido consideráveis modificações a respeito da escola republicana, como analisou Gregolin (2015). Ela ainda mantém intacta a sua maneira de organizar o tempo, o espaço, a vigilância, seja na figura do inspetor de ensino ou de câmeras, os exames etc., e assim controlar os corpos dos alunos e também dos professores.

O termo aula se mantém, dentro da FD do ensino tradicional - ou seja, nas práticas discursivas e pedagógicas vigentes em grande parte das escolas brasileiras -, como um espaço de estabilidade e de manutenção de práticas disciplinares. As práticas pedagógicas tradicionais são percebidas pelo discurso 
do movimento estudantil como alheias, ou com pouca proximidade, à realidade social, assim, essa aproximação se dará em outros espaços de socialização, como nas ruas. Desse modo, a construção utilizada durante as manifestações de 2015, Hoje a aula é na rua, rompe parcialmente com esse sentido do termo aula que é instaurado pela memória da FD do ensino tradicional. Há esse rompimento justamente porque aula/escola (universos que abarcam o campo do ensino tradicional) e rua estão em desajuste discursivo e social: há um discurso já instaurado de que o papel da escola é tirar as crianças e os adolescentes das ruas, termo este que, na formação discursiva em questão (do ensino tradicional), assume o sentido de marginalidade.

No entanto, essa oposição existente entre aula e rua se neutraliza nesse acontecimento, por conta de uma influência externa à FD do ensino tradicional: agora passa também a operar uma memória no enunciado da FD do movimento estudantil - pautada principalmente nos discursos de resistência. Essas duas FDs se interseccionam e possibilitam uma ressignificação de sentidos, que vislumbra a percepção de uma outra realidade possível nas práticas pedagógicas, as quais se

refletiriam além dos muros das escolas. Desse modo, é pertinente ressaltar que as formações discursivas não são estanques, elas se relacionam justamente porque não constituem um espaço fechado.

A FD do movimento estudantil penetra a FD do ensino tradicional e faz deslizar o sentido restrito de aula para uma concepção, também presente no dicionário Houaiss (2009), como "uma ação que constitui um ensinamento". O ensinamento proposto por esses manifestantes vem como resposta às medidas impostas pelo governo estadual de São Paulo, e a ação tomada pelos jovens secundaristas foi a quebra do cotidiano escolar: se as reivindicações contrárias à reestruturação não fossem ouvidas enquanto os estudantes estavam nas salas de aula, cabia a eles tomarem as ruas, palco histórico das conquistas dos direitos sociais.

\section{As ocupações como formuladoras de sentido}


A trama da história renova esse acontecimento enunciativo, o qual circula em diversas manifestações estudantis no Brasil e fora dele. Apesar das constantes repressões, o movimento estudantil possui presença marcante nos diversos movimentos sociais da nossa história, por exemplo, durante a ditadura civilmilitar brasileira, período no qual a resistência se dava por meio de expressões artísticas e produção de jornais clandestinos que denunciavam as atrocidades do regime. É a partir desse período, sob a influência do maio francês dos anos de 1968 e 1969, movimento liderado pelo movimento estudantil da França, que os estudantes no Brasil passaram a reconhecer a sua força e se organizarem em movimentos específicos pela melhoria da qualidade da educação ou de direitos específicos ao seu grupo estudantil. Assim, as greves na educação e as manifestações fizeram cada vez mais que professores e alunos fossem reconhecendo as ruas como espaço de resistência (FREIRE, 2008).

Geralmente, nesses contextos de militância, surgem novos cartazes com dizeres contra as medidas às quais se está opondo. No período de 2015, no estado de SP, por exemplo, os cartazes estampavam dizeres como "Não feche a minha escola", "Da minha escola ninguém vai me tirar", "A escola é nossa", "Contra a reorganização escolar", "Você fecha a minha escola e eu tiro o seu sossego", devido às medidas específicas que a reorganização acarretaria, como o fechamento de escolas. Além desses, outros dizeres apontavam o culpado da situação segundo os estudantes, tais como "Não reforme a escola, reforme o seu governo”, “Geraldo Alckimin exterminador da educação”, “Alckmin inimigo da educação", e muitas escolas usaram o tema "escola de luta" como palavra de ordem.

Outros cartazes ainda se referiam diretamente às táticas executadas pela resistência à reorganização: "Se fechar a gente ocupa", "Ocupar é resistir". Nessa quantidade de enunciados emergidos a partir e contra o projeto de reorganização escolar, outra materialidade reemerge na cena estudantil, que é o enunciado com o qual estamos lidando - Hoje a aula é na rua -, textualizado de diferentes formas no intradiscurso como Agora a aula é na rua ou, com a inversão dos sintagmas, $A$ aula hoje é na rua. Todas essas formulações constituem um enunciado 
pertencente a uma formação discursiva dos estudantes que saem às ruas para se manifestar, deixando a escola e tomando os espaços públicos como forma de protesto e de visibilidade, para que a população possa não somente conhecer as suas reinvindicações, mas também aderir às suas causas.

Esse enunciado dialoga com outros dois: um que afirma ser a rua o lugar por excelência da manifestação, do protesto e da resistência, outro que declara que a aula acontece, geralmente, na escola ou em alguma outra instituição fechada, que não pertence à rua, que está distante da rua. Distante tanto no sentido físico, sendo materialmente um espaço dissociado da rua, geralmente apartado visualmente por grades e/ou muros, onde funciona todo um dispositivo específico escolar, e no sentido abstrato, afinal, as escolas e as ruas são esferas antagônicas, como já comentamos, em que aquelas pregam o discurso de que a educação tira as crianças e os jovens da rua, os acolhe e os educa para os salvar do mundo da criminalidade. Na FD do ensino tradicional, portanto, o termo rua está associado a provações e à marginalidade.

Os termos aula e rua, assim, estão em planos discursivos diferentes que, quando colocados em paralelo com o dêitico hoje (ou agora), nos permitem acessar os sentidos de que aquela manifestação, daquele dia e lugar específico, não é o habitual, não é o "normal" de acordo com o dispositivo escolar, de acordo com o estabelecido na memória educacional tradicional brasileira. O "natural" é que as aulas ocorram nas instituições especializadas para tal atividade, mas no hoje enunciado, respondendo a uma urgência político social, ela se dará em outro espaço, no espaço que não é institucionalmente o escolar, portanto, não no espaço da educação, mas não menos relacionado a ela: no espaço das lutas sociais.

Apesar do termo aula fazer funcionar, na FD do ensino tradicional, os sentidos de hierarquia, conservadorismo, tradição e autoritarismo, onde na relação professor - aluno, o professor é o sujeito que exerce o poder por meio de sua posição de sujeito autorizado a ensinar determinado conteúdo e a ser o sujeito disciplinador, a aula na rua cria outras possibilidades de aprendizagem e ensino. A relação de poder convencional entre professor e aluno fica diluída, outras relações são construídas nesse novo espaço. 
Se aula está relacionada à troca de conhecimento, da rua também podem emergir saberes, pois a luta também ensina. É o que podemos constatar por meio do enunciado da Figura 3, a seguir, em que os professores enunciaram a partir da FD do movimento estudantil, da luta pela educação, assumindo, assim, além de sujeitos professores, outra posição, a de sujeitos professores militantes. Esse enunciado aproxima o sentido do processo do ensinar e do aprender na luta e nas ruas.

\section{Figura 3}

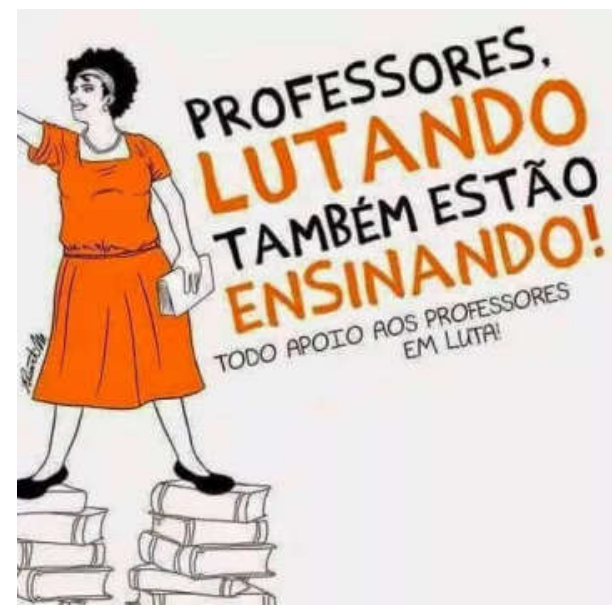

Fonte: Professores unidos pela liberdade de cátedra (Facebook)

Dizer que hoje a aula será na rua, poderia significar, em outro momento histórico, ou a partir de outras formações discursivas, como a do ensino tradicional, ou materializados a partir de outros sujeitos, simplesmente uma aula que se daria, por algum motivo, na rua e não no espaço escolar, como alguma gincana nas aulas de educação física, alguma pesquisa de campo em aulas de biologia, geografia etc. No entanto, a leitura que fazemos desse enunciado precisa estar em cotejo com o acontecimento social do momento histórico específico: a reorganização escolar, um projeto que despertou rapidamente a revolta da comunidade escolar.

Se esse acontecimento emerge em diversos momentos nas lutas dos movimentos estudantis, os sentidos produzidos em cada momento histórico são 
modificados. Desse modo, é necessário analisar a fundo as condições peculiares ao momento histórico em que dado enunciado foi produzido, pois

\begin{abstract}
Por mais banal que seja, por menos importante que o imaginemos em suas consequências, por mais facilmente esquecido que possa ser sua aparição, por menos estendido ou mal decifrado que o suponhamos, um enunciado é sempre um acontecimento que nem a língua nem o sentido podem esgotar inteiramente. Trata-se de um acontecimento estranho, por certo: inicialmente porque está ligado, de um lado, a gesto da escrita ou à articulação de uma palavra, mas, por outro lado, abre a si mesmo uma existência remanescente no campo de uma memória, ou na materialidade dos manuscritos, dos livros e de qualquer forma de registro; em seguida, porque é único como todo acontecimento, mas está aberto à repetição, à transformação, à reativação (FOUCAULT, 2000, p. 32).
\end{abstract}

A unicidade presente no enunciado analisado se compreende a partir do momento que ressaltamos a singularidade histórica que possibilitou a sua emergência, porque é ela que vai reativar os novos sentidos. Nesse aspecto, ressaltamos que as manifestações estudantis de 2015 foram marcadas pelas ocupações de escola, método de resistência articulado pelos estudantes secundaristas para serem ouvidos pela secretaria da educação.

Essa tática foi utilizada em mais de 200 estabelecimentos de ensino, algumas ocupações duraram cerca de quarenta dias. Nesse período, havia atividades transversais, inclusive aulas abertas a toda comunidade do bairro, e a construção de um espaço autônomo, com os jovens cozinhando suas refeições e organizando, do seu modo, o espaço escolar. Salas de aula se transformaram em quartos, pátios foram convertidos em espaços de socialização, onde ocorriam desde aulas abertas e momentos de lazer, até as decisões que determinariam os próximos passos do movimento, como as reuniões e assembleias. Do mesmo modo, as ruas ficaram repletas de estudantes uniformizados empunhando cartazes sobre a educação, sobre suas escolas, gritando palavras de ordem em defesa do ensino que acreditavam e, em alguns casos, carteiras também foram trazidas às ruas num gesto de transformação do espaço público. $\mathrm{O}$ enunciado em questão é materializado não só no verbal, mas por meio dos corpos - os alunos, identificados como alunos pelos uniformes, estão ocupando não só as escolas 
como as ruas -, e por meio dos objetos próprios (livros e carteiras) do ambiente escolar.

Assim, o dêitico hoje, nesse contexto específico do movimento estudantil de 2015, assume um marco temporal que acompanha a originalidade da tática. Hoje a aula é na rua é um enunciado característico do movimento do professorado ou do movimento estudantil, o qual sugere que o espaço escolar, esvaziado pelas práticas obsoletas de ensino, se pulverizou e invadiu os espaços públicos, atribuindo um sentido de "aula" distinto do que era reconhecido normalmente. $\mathrm{O}$ "hoje" manifesta a temporalidade desse acontecimento e marca o enunciado como transgressor, já que esse dêitico define o não-amanhã e o nãoontem para a realização da tática de ocupar as ruas. Portanto, esse termo sinaliza a negação do espaço-tempo da normalidade e da rotina escolar.

A escola, quando tomada e apropriada pelos estudantes militantes, corresponde ao modo como eles enxergam o lugar que tem como pressuposto estimular o pensamento crítico e a autonomia:

\begin{abstract}
Os secundaristas romperam o isolamento individualista do cotidiano escolar e criaram uma nova sociabilidade no processo de luta: uma sociabilidade baseada na corresponsabilidade, na horizontalidade dos processos decisórios e no cuidado do patrimônio público. Essas novas relações são o que a tradição autonomista chama de política préfigurativa, a capacidade de forjar, no próprio processo de luta, as formas sociais a que se aspira, fazendo convergir meios e fins. A sociabilidade horizontal, corresponsável e baseada na proteção do patrimônio público é, ao mesmo tempo, objetivo da luta e criação imediata, uma espécie de antecipação performativa daquilo que se busca (ORTELLADO, 2016, p.13).
\end{abstract}

A aula, portanto, na concepção de ensinamento, dada por eles, dentro do espaço escolar, demonstra a possibilidade efetiva de exercerem uma prática autônoma e política durante todo o período letivo - não só durante essa ruptura com a normalidade - ou seja, os estudantes presenciaram ativamente a transformação da realidade.

O fato de eles estarem ocupando o espaço escolar não os impediu de irem às ruas mostrar à comunidade suas reivindicações; fazer a aula na rua hoje (naquele momento) possui um sentido específico nessa condição histórica proporcionada pelos estudantes. Se a escola tradicional muitas vezes ignora a 
realidade social, esse gesto efetivado pelos estudantes nas ruas é um desdobramento das práticas colocadas dentro das escolas ocupadas por eles, ou seja, a autonomia e a percepção da necessidade de serem ouvidos transpassam os muros e invadem os espaços públicos, abertos, sem grades, sem a disciplina que atua sobre os seus corpos dentro da instituição.

\section{Da escola ocupada à rua tomada}

Rua é um enunciado expressivo, pertencente ao discurso das lutas sociais, que compõe outros enunciados, como a famosa palavra de ordem de 2013 do movimento contra a corrupção "Vem pra rua, vem", ou até mesmo em discursos fundadores como "la beauté est dans la rue", materializado em um emblemático cartaz (Figura 3) que circulou na França durante a histórica mobilização estudantil de 1968.

Figura 4 - A beleza está nas ruas

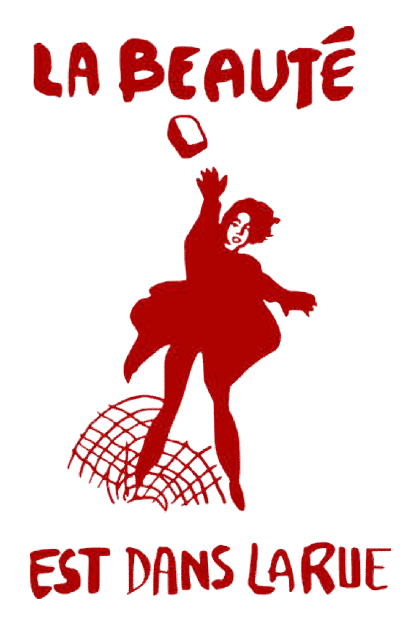

Fonte: 68: como incendiar um país (2018)

No cartaz a materialidade verbal se une à imagem, uma estudante usando os paralelepípedos das ruas como arma e como proteção. 
O fato de algum movimento político convocar a população para as ruas faz com que esse enunciado seja significativo e palco de resistência no século XX e em períodos anteriores. Segundo Mikhail Bakhtin (1999), em sua tese sobra a cultura popular na Idade Média e no Renascimento, a rua, a praça pública é o lugar de inversão da ordem social, da crítica aos bons costumes. É nela que são realizadas as transgressões do povo, em que os sujeitos se encontram com os outros e sentem-se pertencentes "ao grande corpo popular" (BAKHTIN, 1999, p.222).

\begin{abstract}
É a rua que permite a transgressão como lugar de rememoração de suas próprias histórias. Na rua, vida e sonho se interligam, submersos na textura forte dos dizeres e fazeres dos brincantes, dos carnavalescos, do folião, do povo. Sempre o lugar de embate, de confronto, de Vicência é a rua, ela é para os brincantes o palco que os colocam no centro da cena, é o lugar em que podem resistir ao esquecimento, é onde clamam por reconhecimento de seus atos, das suas histórias, das suas vidas, de si próprios e de sua cultura popular (PAJEÚ, 2014, p. 175).
\end{abstract}

Ao contrário do espaço privado, onde o sagrado, a família e a individualidade atuam, a praça pública é onde a distância entre o eu e o outro é parcialmente abolida, a liberdade das ruas suprime as ideologias oficiais, as "barreiras hierárquicas que separam os indivíduos, e se estabelece um contato familiar real" (BAKHTIN, 1999, p. 163).

O enunciado analisado suscita a memória da rua como espaço de destronamento do poder, em que os jovens invadem as ruas para serem ouvidos e se colocam como um grande corpo social, unidos pelo mesmo ideal: frear a reorganização escolar. Os gritos de ordem, as sátiras dos cartazes, muitas vezes, tendo como alvo da sátira o então governador e o secretário da educação, são a materialização do nascedouro de uma nova realidade, porque ao degradar essas figuras do alto escalão do estado, se esboça não apenas um "valor destrutivo, negativo, mas também um positivo, regenerador: é ambivalente, ao mesmo tempo negação e afirmação. (...) o baixo é sempre o recomeço" (BAKHTIN, 1999, p. 19).

A resistência à reorganização é um recomeço, é reabertura da possiblidade dos estudantes continuarem em suas escolas, que é o seu espaço de socialização. Com as escolas já ocupadas pelos secundaristas, cabia a eles próprios, agora, 
tomar as ruas como estratégia de pressionar o governo estadual de São Paulo e, ao provocar esse acontecimento, ressignificar a concepção de aula do ensino tradicional.

Entendendo por resistência o ato de reagir contra algo que se quer mudar, encaramos que a prática discursiva e não discursiva dos secundaristas foi uma resistência a certas medidas políticas que eles não aceitavam. A resistência para Foucault (1995; 2008), no entanto, vai além de manifestações organizadas contra o estado ou a uma instituição, como os protestos nas ruas ou as ocupações. Resistir pode ser também uma objeção ao modo de ser sujeito que está instaurado, ou a um discurso que quer participar como verdade de nossa subjetivação. Assim, quando a escola prega um modo de ser aluno, estudioso obviamente, mas também disciplinado, obediente, que frequenta e participa das aulas no sentido institucional e tradicional do termo, ela está objetivando os sujeitos alunos, criando um padrão de normalidade para suas condutas. Quando o aluno vai às ruas lutar pelo modelo educacional que quer, pedir mais investimentos na educação ou simplesmente pedir que não fechem a sua escola, ele está resistindo às medidas do governo, mas ele está também resistindo a essa objetivação, onde a posição do sujeito aluno não corresponde a como o sujeito aluno-militante se reconhece.

Assim, ao enunciar que a aula é na rua, tanto os termos aula e rua estão sendo deslocados da formação discursiva "natural" da escola tradicional e sendo realocados na formação discursiva do movimento estudantil quanto o próprio sujeito aluno está ressignificando os sentidos para a sua construção enquanto aluno militante, que luta pelos direitos e pela melhoria da educação.

\section{Considerações finais}

A partir das nossas discussões em torno do enunciado "Hoje a aula é na rua”, vimos que as lutas estudantis, sobretudo a da escola estadual paulista, dos últimos três anos constituem uma forma de resistência dupla: ao mesmo tempo 
em que o aluno resiste às medidas do governo com as quais ele não concorda, como a reorganização escolar, ele também resiste às formas de ser sujeito aluno criadas pelo dispositivo escolar.

A partir do momento em que o aluno é colocado frente a novas discursividades, que aproximam os termos usados na formação discursiva do modelo de ensino escolar tradicional e na formação discursiva do movimento estudantil, tanto aula quanto rua recebem um novo sentido e a posição do sujeito aluno também é ressignificada. O aluno não é somente aquele que frequenta as aulas, num espaço institucional específico, que obedece às regras ou é castigado por subvertê-las. O aluno que se inscreve no enunciado "hoje a aula é na rua", constrói novas formas de ser sujeito, se identifica com o sujeito que além de aluno do modelo tradicional, submetido às disciplinas próprias da instituição, vai às ruas aprender e ensinar a lutar por um sistema educativo, por uma escola que ele sente como sua, como uma extensão da sua subjetividade. Agora ele é um sujeito que vai às ruas protestar, gritar e ser ouvido, fazer outro uso do seu corpo, não mais dócil e obediente às regras do dispositivo escolar, mas que não deixa de ser um corpo produtivo, útil à outra ordem discursiva, à ordem da militância, rebelde às regras da instituição que frequenta e às imposições do governo, enunciando a partir desse outro lugar.

\section{Referências}

BAKHTIN, M. A cultura Popular na idade média e no Renascimento: o contexto de François Rabelais. Brasília: Hucitec, 1997.

BELISARIO, Y. 'Hoy la clase es en la calle', la protesta creativa de los Ucabistas”. Disponível em http://rumbacaracas.com/noticias/2014/03/28/la-ucab-continuacon-las-protestas-creativas/. Visitado em 10 de setembro de 2018.

COURTINE, J. Análise do discurso político: o discurso comunista endereçado aos cristãos. São Carlos: Edufscar, 2009.

COSTA, Rogério da. Sociedade de controle. São Paulo Perspec. São Paulo, v.18, n 1 p. $161-167,2004$ 
DELEUZE, Gilles. Controle e devir. In. . Conversações (1972-1990). Rio de Janeiro: Ed. 34, 1992, p. 209-218

DREYFUS, H.; RABINOW, P. Michel Foucault: uma trajetória filosófica. Rio de Janeiro: Forense Universitária, 1995.

FOUCAULT, M. M Foucault. Conversação sem complexos com um filósofo que analisa as "estruturas do poder" (1978). In: Ditos e escritos IV: estratégia, podersaber. Org. Manoel Barros da Mota. Trad. Vera Lúcia A. Ribeiro. Rio de Janeiro: Forense Universitária, 2003.

A arqueologia do saber. 6.ed.Rio de Janeiro: Forense Universitária, 2000. . Vigiar e Punir. Trad. Raquel Ramalhete. 20 ed. Petrópolis: Editora Vozes, 1999.

. O sujeito e o poder. In: DREYFUS, H.; RABINOW, P. Michel Foucault: uma trajetória filosófica. Rio de Janeiro: Forense Universitária, 1995. pp. 241-249. FREIRE, S. de M. Movimento estudantil no Brasil: lutas passadas, desafios presentes. Rhela. Vol 11. 2008, pp. 131-146.

GREGOLIN, M.do R.V. O dispositivo escolar republicano na paisagem das cidades brasileiras: enunciados, visibilidades, subjetividades. Revista Moara, n 43, 2015.

. Formação discursiva, redes de memória e trajetos sociais de sentido: mídia e produção de identidades. In. BARONAS, R.L. (org). Análise do Discurso: apontamentos para uma história da noção-conceito de formação discursiva. São Carlos: Pedro \& João, 2011.

Análise do discurso e mídia: a (re)produção de identidades. Comunicação, Mídia e consumo. São Paulo, v. 4, n.11, p. 11-25, 2008.

LOPONTE, L. G. Foucault com Nietzsche: do Nietzsche trágico ao Foucault ético: sobre estética da existência e uma ética para a docência. Educação e Realidade. v. 28, n. 2, p. 69-82, 2003.

MHEREB, M.T. A beleza está nas ruas. In: MHEREB, M.T; CORRÊA, E. 68 como incendiar um país. São Paulo: Veneta, 2018. 
MENEGUETTI, G.; SAMPAIO, S.S. A disciplina como elemento constitutivo do modo de produção capitalista. Revista Katál, Florianópolis, v. 19, n. 1, p. 135-142, 2016.

NOTO, C. de S. A ontologia do sujeito em Michel Foucault. Dissertação (Mestrado em Filosofia). 147f. 2009. Universidade de São Paulo, 2009.

O Mal educado. Página do facebook. Figura 1 publicada no dia 1 de dezembro de 2015. Disponível em https://www.facebook.com/mal.educado.sp/photos/pb.291834600950292.2207520000.1461937386./726375684162846/?type=3\&theater. Visitado dia 10 de setembro de 2018 .

O Mal educado. Página do facebook. Figura 2 publicada no dia 2 de dezembro de 2015 . Disponível

em https://www.facebook.com/mal.educado.sp/photos/a.503085239825226/7268970 84110706/?type=3\&theater. Visitado dia 10 de setembro de 2018.

ORTELLADO, P.Prefácio. In:CAMPOS, A.M; MEDEIROS, J.;RIBEIRO, M. Escolas de luta. São Paulo: Veneta(Coleção Baderna), 2016.

SÁ, l. de. Memória discursiva da ditadura no século XXI: visibilidades e opacidades democráticas. 2015. 23of. Tese (Doutorado em Linguística). Universidade Federal de São Carlos, 2015.

Recebido em 16/o9/2018.

Aprovado em 14/12/2018. 